$\left.\begin{array}{c}\text { INTERNATIONAL JOURNAL OF } \\ \text { ORGANIZATIONAL LEADERSHIP }\end{array}\right) \begin{gathered}\text { INDUSTRIAL } \\ \text { MANAGEMENT } \\ \text { INSTITUTE }\end{gathered}$

\title{
Effect of intrinsic rewards on task performance of employees: Mediating role of motivation
}

\author{
Rizwan Qaiser Danish ${ }^{1}$, Muhammad Khalid Khan ${ }^{2}$, Ahmad Usman Shahid ${ }^{3}$, Iram \\ Raza $^{4}$, Asad Afzal Humayon ${ }^{5}$ \\ ${ }^{1,2,3}$ Hailey College of Commerce, University of the Punjab, Lahore, Pakistan \\ ${ }^{4}$ Minhaj University, Lahore, Pakistan \\ ${ }^{5}$ COMSATS Institute of Information Technology, Vehari, Pakistan
}

\begin{abstract}
Keywords:

Reward Management System, Intrinsic Rewards, Intrinsic Motivation, Extrinsic Motivation, Task Performance, Banking Sector

Correspondence:

Rdanish2000@yahoo.co.uk

The basic purpose of this study was to examine the effect of reward management system, especially intrinsic rewards on task performance with the mediating role of extrinsic and intrinsic motivation of employees working in the banks in the capital of Punjab, Lahore, Pakistan. The secondary purpose of this study was to explore what level of performance these employees demonstrate towards their organizations when they are rewarded intrinsically and when they are motivated due to these reward management system accordingly. In this study, we collected data through self-administered questionnaires applying correlational explanatory research design. We distributed 300 questionnaires among which 290 were returned resulting in a response rate of $96 \%$. The analysis of the data revealed that intrinsic rewards have positive impact on task performance of employees working in banks and motivation and its dimensions, i.e., intrinsic motivation, extrinsic motivation, and job satisfaction mediated this relationship. Considering the importance of appreciations received by bankers in the form of rewards and their effect on extra role performance and sophisticated management, policy makers should take necessary steps for improving the reward management system which will increase the task performance of employees because they will be motivated by these performance appraisal techniques.
\end{abstract}

(C)AIMI Journals

\section{Introduction}

Organizations which want to excel in a competitive market need some factors that boost up an organization to work hard to achieve this goal. The most important factor in any organization is work force. Any organization can develop itself by motivating and enhancing 
the efficiencies of their workers by implementing some sort of appreciation techniques. Reward management system is one of the most practicable appreciation techniques and it is the main feature of human resource management to attract and retain talented employees by motivating them to perform well. Markova and Ford (2011) argued that readiness of workers to use their creativeness, skills, and knowledge determines the success of an organization. For improving the performance of employees, benefits, and incentives can be used as an effective tool. Organizations try to intrinsically and extrinsically motivate and increase the task performance of their personnel by adopting various human resources practices. Unfavorable salary for employees' performance might result in low motivation level and job dissatisfaction. For success of any organization, it should invest in making their employees skillful for performing specific task. Social exchange theory argued that when an organization invests in the development of personnel, then they act in a constructive way for the wellbeing of organization (Cropanzano \& Mitchell, 2005). The purpose of our study was to explore the relationship between intrinsic rewards and task performance of employees with the mediating role of extrinsic motivation, intrinsic motivation, and job satisfaction of employees. Employee's task performance was defined as what a worker perform or does not perform. Task performance of employees includes relevance, quantity, quality of output, and cooperativeness.

\section{Reward Management System}

Rewards are the most important techniques to keep employees motivated in accomplishing their tasks. The findings of studies carried out to date indicate that rewards system play a vital role in motivating employees so that they can perform creatively (Eisenberger \& Rhoades, 2001). Organization's procedures, policies, and implications constitute the reward management system and organizations reward their employees according to their participation, skills, and performance. For the purpose of obtaining the strategic goals and creating a helpful working environment, reward system is necessary for any organization to retain and attract skilled and competent employees (Galbraith, 1973). Reward is the remuneration that an employee receives in return for the work and services he or she had performed in the organization (Goodale, Koerner, \& Roney, 1997). They further explained that only monetary forms do not constitute reward, it also includes those that are difficult to explain in monetary terms. Many examples include chances of future growth, flexible working environment, and participation in decision-making. Reward management system 
plays a central role in human resource management; it comprises both financial and nonfinancial rewards that are also called extrinsic rewards.

Rusbult and Farrell (1983) proposed that emotions of lust, eagerness, commitment, and self-sufficiency constitute intrinsic rewards. Abdullah (1994) proposed that extrinsic rewards include compensation, coworker's behavior, and security of job. Yang (2008) proposed that appreciation and praise, promotion and title, authority and responsibility, education, proposal of work, certificate and plague, contribution to decision making, vacation time, favorable working hours, comfort of working environment, social activities, feedback, gratitude, social rights, bonus system, perquisites, and increase in pay are included in extrinsic rewards. For better performance of employees, intrinsic rewards are equally important as extrinsic rewards to keep them motivated (Harpaz, 1990).

According to Awasthi and Pratt (1990), intrinsic rewards develop a persistent motivation and mutual benefit to both employees and organization they served. Extrinsic rewards motivate employees to give more time to the assigned task, put more efforts on it, and increase their performance (Klein, Goodhue, \& Davis, 1997). Rewards and appreciation affects the motivation of employees significantly (Danish \& Usman, 2010).

\section{Motivation}

The Latin word movere, is the origin of the term motivation, means to move (Baron, Henley, McGibbon, \& McCarthy, 2002). Amabile, Hill, Honnessey, and Tighe (1994) proposed that motivation is the base factor for learning purpose. Motivation is an approach that stimulates, modifies viewpoint, and encourages good behavior and performance of employees (Luthans \& Sommer, 2005). Motivation is like a vision that stimulates a person to perform because human behavior is attracted by some desired goal (Demirci, 2007). Bhatnagar (2007) proposed that motivation is a personalized instinct in human nature and can be segregated into extrinsic and intrinsic motivation.

Vroom (1964) proposed the expectancy theory of motivation in which he introduced new ideas of expectancy, valence, and instrumentality. According to him, expectancy can be defined as surety that the task performed by an employee would motivate him to accomplish expected performance. Instrumentality states that an employee will receive a reward if his or her performance is well. He refers to the importance that an employee gives to rewards received for better task performance. According to expectancy theory, the positive outcomes are perceived to be caused by a given action that makes the people more motivated towards 
performing that specific action. Equity theory developed by John Stacy Adams in 1963, explained that employers should give equal and same rewards to all employees. He further stressed that employees working in any organization want impartiality between the efforts that they place in their job and the returns they receive for their work. This theory suggests that when an employee believes that his coworkers receive the equal and same reward, they get motivated due to this belief. Low turnover, commitment to the organization, and satisfaction with job determines the motivation of employees (Nohria, Groysberg, \& Lee, 2008). Kinicki and Kreitner (2006) proposed that motivation is a psychological process that causes the inspiration and determination of intentional acts that are objective-oriented. In this study, we concentrated on dimensions of motivation which are extrinsic and intrinsic motivations; job satisfaction was also studied here as mediation variable of motivation between intrinsic rewards and task performance of employees.

Intrinsic motivation refers to tendency of human being to learn while extrinsic motivation reflects true self-regulation. In self-determination theory which Deci and Ryan (1985) proposed, intrinsic motivation refers to doing something due to our interest in that particular task or activity and extrinsic motivation refers to doing something because of its desired results. When a person is intrinsically motivated, he or she moves to perform for some sort of contest entailed rather than due to work pressure, rewards, or external stimulus. Skinner (1953) proposed reinforcement theory arguing that result of any specific event or circumstance drives the behavior of human. Actually, reinforcement is a specific term of operant conditioning in which consequences of any pleasant or unpleasant event modify the behavior of an individual. Deci and Ryan (1985) presented cognitive evaluation theory (CET) explaining the factors which play key roles in intrinsic motivation; social occurrences and structures including rewards and positive responses contribute substantially to emotions of proficiency during any action and develops intrinsic motivation for that particular action because they create a feeling of satisfaction related to the elementary psychosomatic needs, desired for professional competency. Extrinsic motivated is executed because of some distinguishable consequence and they can vary in the scope to which they characterize selfdetermination.

\section{Job Satisfaction and Task Performance}

Job satisfaction is the degree of satisfaction or dissatisfaction of employees with their jobs (Spector, 1997). Milne (2007) and Leete (2000) claimed that rewards and appreciations have 
some sort of relationship with results and outcomes expected to fluctuate because of satisfaction with their institute. Amabile, Hill, Hennessey, and Tighe (1994) argued that employees who are satisfied with their job are motivated by rewards. Previous research indicated that reward system encourages employees to perform well in their organization. Improvement in employee's performance will ultimately enhance the performance of organization resulting in maintaining their global competitive advantage. Task performance of an individual is essential for the career growth of an employee. The main objective of any organization is achieving its planned target and it can be accomplished by performance management system including task performance and extra role performance of employees.

\section{Hypotheses}

$\mathbf{H}_{1}$ : There is a relation between intrinsic rewards and task performance of employees.

$\mathbf{H}_{2 \mathbf{a}}$ : There is a relation between intrinsic rewards and intrinsic motivation of employees.

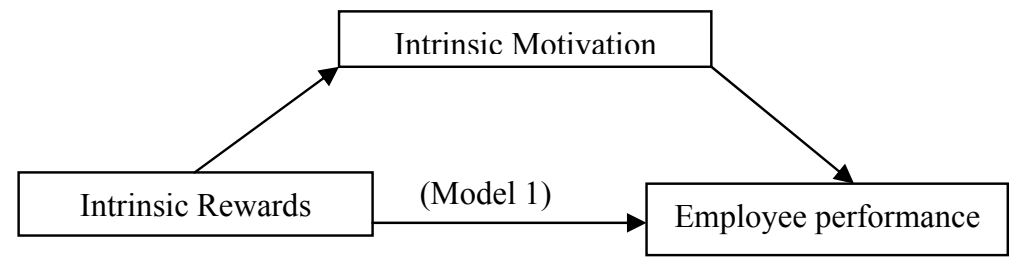

Figure 1. Intrinsic motivation as a mediator

$\mathbf{H}_{2 \mathbf{b}}$ : There is a relation between intrinsic motivation and task performance of employees.

$\mathbf{H}_{3 \mathbf{a}}$ : There is a relation between intrinsic reward and extrinsic motivation of employees.

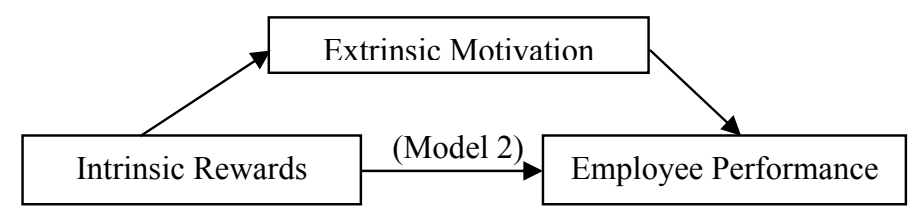

Figure 2. Extrinsic motivation as a mediator

$\mathbf{H}_{3 \mathbf{b}}$ : There is a relation between extrinsic motivation and task performance of employees.

$\mathbf{H}_{4 \mathbf{a}}$ : There is a relation between intrinsic reward and job satisfaction of employees.

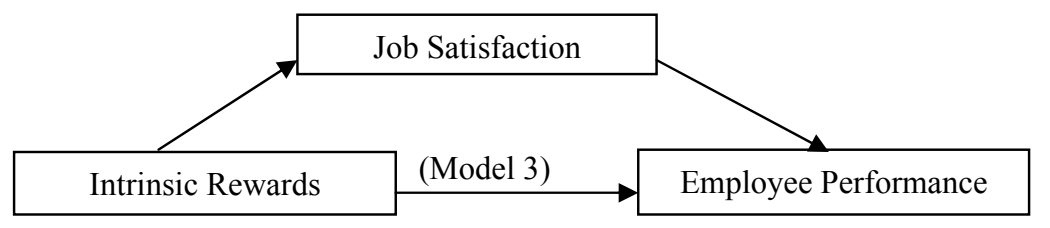

Figure 3. Job satisfaction as a mediator 
$\mathbf{H}_{\mathbf{4 b}}$ : There is a relation between job satisfaction and task performance of employees.

\section{Method}

We distributed the developed questionnaire among three hundred personnel employed in public and private sector banks of Lahore, Pakistan to get maximum responses. Of 300 circulated questionnaires, total functional answered rate was about 96 percent (290). Fivepoints Likert scale was used to measure relation between intrinsic rewards and intrinsic motivation, extrinsic motivation, job satisfaction, and employee task performance. Responses were collected on a 5-point Likert scale ranging from 5 strongly agreed to 1 strongly disagreed. Hypotheses were verified by correlation analysis with the help of SPSS and structural equation modeling (SEM) using AMOS 18.

\section{Data Analysis and Hypotheses Testing}

The data is of primary nature as it was gathered from the personnel of banking sector of Pakistan by a research questionnaire and then its hypotheses were verified by correlation analysis. Table 1 represents the descriptive statistics, reliability coefficients, and Pearson correlation statistics of independent, dependent, and mediating variables. The mean value for intrinsic rewards was 3.86 and for employee performance was 4.06. The correlation results showed that there was a significant relation between intrinsic rewards, intrinsic motivation, and employee performance.

Table 1

Descriptive Statistics of First Model

\begin{tabular}{lcccccc}
\hline \multicolumn{1}{l}{ Descriptive Statistics of First Model } & Mean & SD & Reliability $\alpha$ & $\begin{array}{l}\text { Intrinsic } \\
\text { Rewards }\end{array}$ & $\begin{array}{c}\text { Intrinsic } \\
\text { Motivation }\end{array}$ & $\begin{array}{l}\text { Employee } \\
\text { Performance }\end{array}$ \\
\hline Intrinsic Rewards & 3.86 & 0.69 & 0.66 & 1 & & 1 \\
Intrinsic Motivation & 3.92 & 0.68 & 0.74 & $.54^{* *}$ & $.43^{* *}$ & $.52^{* *}$ \\
Employee Performance & 4.06 & 0.59 & 0.68 & 1 & 1 \\
\hline
\end{tabular}

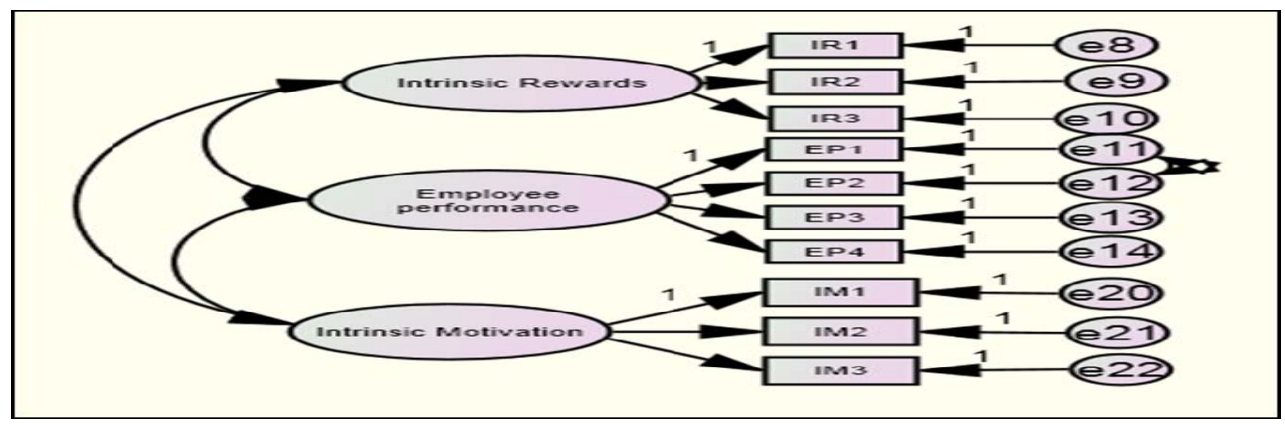

Figure 4. Structural model relating intrinsic rewards to intrinsic motivation and employee performance of first model 
Table 2

Standardized Regression Weights

\begin{tabular}{lcc}
\hline Latent Variable & Item label & Standardized Factor Loading \\
\hline Intrinsic Rewards & IR 1 & .64 \\
& IR 2 & .60 \\
Intrinsic Motivation & IR 3 & .64 \\
& IM 1 & .65 \\
Employee Performance & IM 2 & .72 \\
& IM 3 & .75 \\
& EP 1 & .50 \\
& EP 2 & .57 \\
& EP 3 & .64 \\
EP 4 & .56 \\
\hline
\end{tabular}

\section{Evaluating Measurement Model Fitness}

AMOS provides a set of indices that are implemented to analyze whether or not the data authenticates the hypothesized model. In this study Chi-Square, CMIN/DF, comparative fit indices (CFI), goodness of fit index (GFI), adjusted goodness of fit index (AGFI), and route mean square error of approximation (RMSEA) were used to evaluate the model fitness. These parameters explained the extent to which the variables were associated with one another. Table 2 and Figure 4 illustrate the results. As Table 3 indicates, the measurement model recognized as a good fit with the standards of Chi-Square, CMIN/DF, CFI, GFI, AGFI, RMR, RMSEA, and PCLOSE indices.

Table 3

Model Fit Summary

\begin{tabular}{ccc}
\hline Model Fit Indices & Measurement & Threshold \\
\hline CMIN/DF & 2.18 & $<3$ good ; $<$ permissible \\
CFI & 0.95 & Closer to $1 ;$ good \\
GFI & 0.95 & $>0.90$ \\
AGFI & 0.92 & $<0.80$ \\
RMR & 0.03 & $<0.06$ \\
RMSEA & 0.06 & $<0.06$ \\
PCLOSE & 0.12 & $>0.05$ \\
\hline
\end{tabular}

\section{Structural Equation Modeling for First Model}

SEM tests the relationship between observed and unobserved variables. Initially, overall model fitness was formulated; then, the researcher observed whether specific paths were significant or not as illustrated in Figure 5. In this model intrinsic rewards draws from intrinsic motivation (mediating variable) towards employee performance. Table 4 exhibits the model fitness by applying model fit indices mentioned. CMIN/DF value was 3.35 which suggests that the above model was permissibly fit because its value was lower than 5 . The value of GFI and AGFI indicated that the model had fitness because all values were close to 
0.90. RMSEA and RMR values were 0.09 and 0.00 which were below from 0.10 indicating that the estimated model was statistically fit. All resultant fit indices showed that the fitness of model was acceptable as illustrated in Table 4.

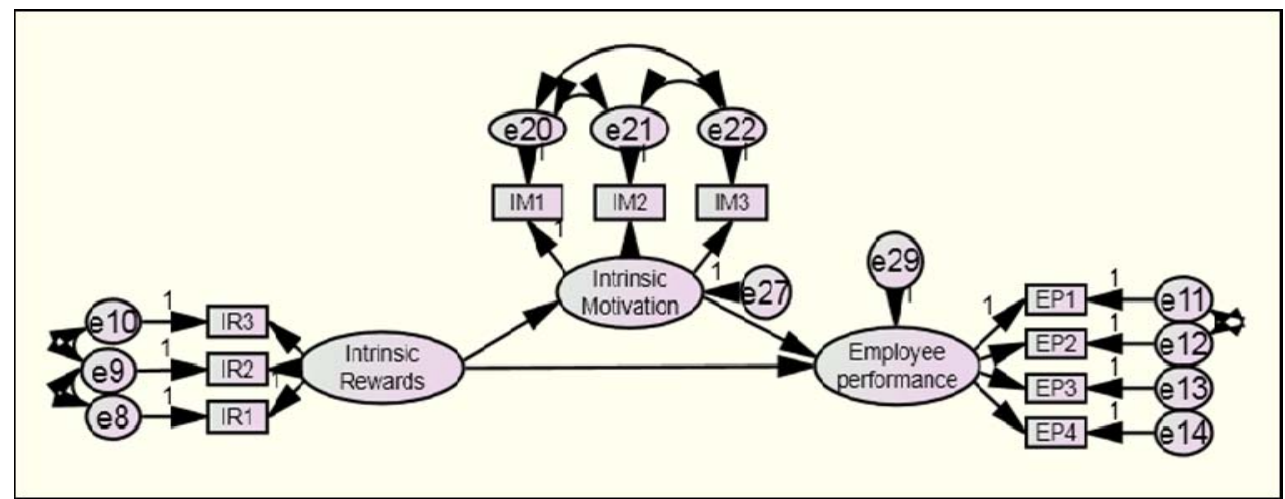

Figure 5. Structural model relating intrinsic rewards to intrinsic motivation and employee performance

Table 4

Model Fitness

\begin{tabular}{ccccccc}
\hline CMIN/DF & RMR & GFI & AGFI & CFI & RMSEA & PCLOSE \\
\hline 3.35 & 0.05 & 0.91 & 0.86 & 0.95 & 0.09 & 0.00 \\
\hline
\end{tabular}

\section{Standardized Estimates}

These variables indicated significant and positive association with one another because regression weight of relationships exceeded 0 as illustrated in Table 5.

Table 5

Standardized Regression Weights of First Model

\begin{tabular}{cccc}
\hline & & & Estimate \\
\hline Intrinsic Motivation & $<---$ & Intrinsic Rewards & .53 \\
Employee Performance & $<---$ & Intrinsic Motivation & .41 \\
Employee Performance & $<---$ & Intrinsic Rewards & .34 \\
\hline
\end{tabular}

\section{Data analysis of Second Model}

Table 6 reveals the descriptive statistics of intrinsic rewards, extrinsic motivation, and employee performance.

Table 6

Descriptive Statistics of Second Model

\begin{tabular}{lcccccc}
\hline & Mean & $\begin{array}{c}\text { Standard } \\
\text { Deviation }\end{array}$ & $\begin{array}{c}\text { Reliability } \\
\alpha\end{array}$ & $\begin{array}{c}\text { Intrinsic } \\
\text { Rewards }\end{array}$ & $\begin{array}{c}\text { Extrinsic } \\
\text { Motivation }\end{array}$ & $\begin{array}{c}\text { Employee } \\
\text { Performance }\end{array}$ \\
\hline Intrinsic Rewards & 3.86 & 0.69 & 0.66 & 1 & & \\
Extrinsic Motivation & 3.71 & 0.71 & 0.65 & $.57^{* *}$ & 1 & 1 \\
Employee & 4.06 & 0.59 & 0.68 & $.43^{* *}$ & $.43^{* *}$ & 1 \\
Performance & & & & & & \\
\hline
\end{tabular}




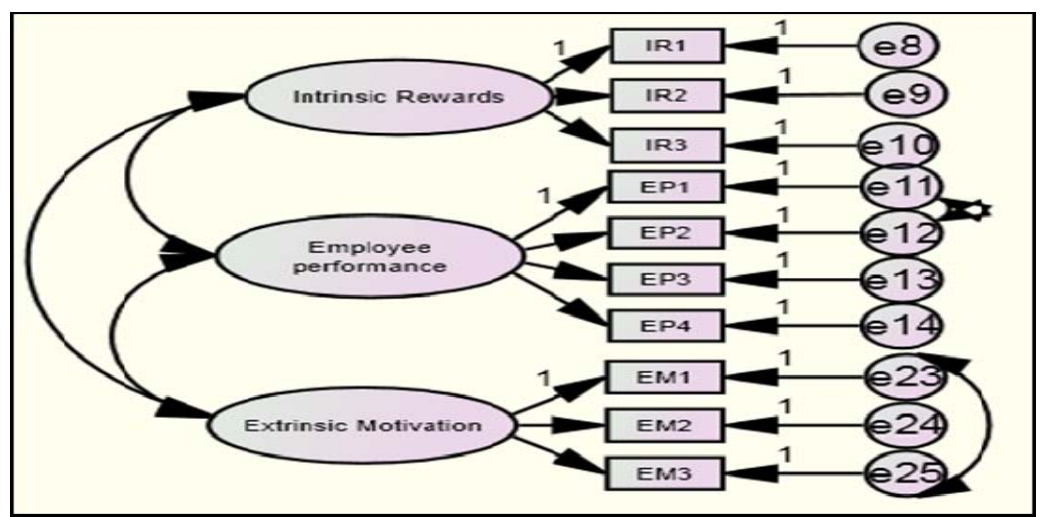

Figure 6. The measurement model of second model

As Figure 6, Table 7, and Table 8 indicate, the measurement model recognized as a good fit.

Table 7

Standardized Regression Weights of Second Model

\begin{tabular}{ccc}
\hline Latent Variable & Item Label & Standardized Factor Loading \\
\hline Intrinsic Rewards & $\mathrm{IR}_{1}$ & .60 \\
& $\mathrm{IR}_{2}$ & .62 \\
Extrinsic Motivation & $\mathrm{IR}_{3}$ & .67 \\
& $\mathrm{EM}_{1}$ & .69 \\
Employee Performance & $\mathrm{EM}_{2}$ & .63 \\
& $\mathrm{EM}_{3}$ & .65 \\
& $\mathrm{EP}_{1}$ & .47 \\
& $\mathrm{EP}_{2}$ & .57 \\
Table 8 & $\mathrm{EP}_{3}$ & .70 \\
Model Fit Summary of Second Model & $\mathrm{EP}_{4}$ & .52 \\
\hline Model Fit Indices & & \\
CMIN/DF & & Threshold \\
CFI & Measurement & Closer to $1 ;$ good \\
GFI & 1.98 & $>0.90$ \\
AGFI & 0.95 & $<0.80$ \\
RMR & 0.96 & $<0.06$ \\
RMSEA & 0.92 & $<0.06$ \\
PCLOSE & 0.03 & $>0.05$ \\
\hline
\end{tabular}

\section{Structural Equation Modeling for Second Model}

CMIN/DF value was 2.64 which suggested that the above model was fit because its value was lower than 3. The value of GFI and AGFI showed that the model had fitness because all values were close to 0.90 . RMSEA and RMR values were 0.07 and 0.005 which were below 0.10 proposing that the estimated model was statistically fit as illustrated in Figure 7 and Table 9. All resultant fit indices showed that the fitness of model was acceptable. 


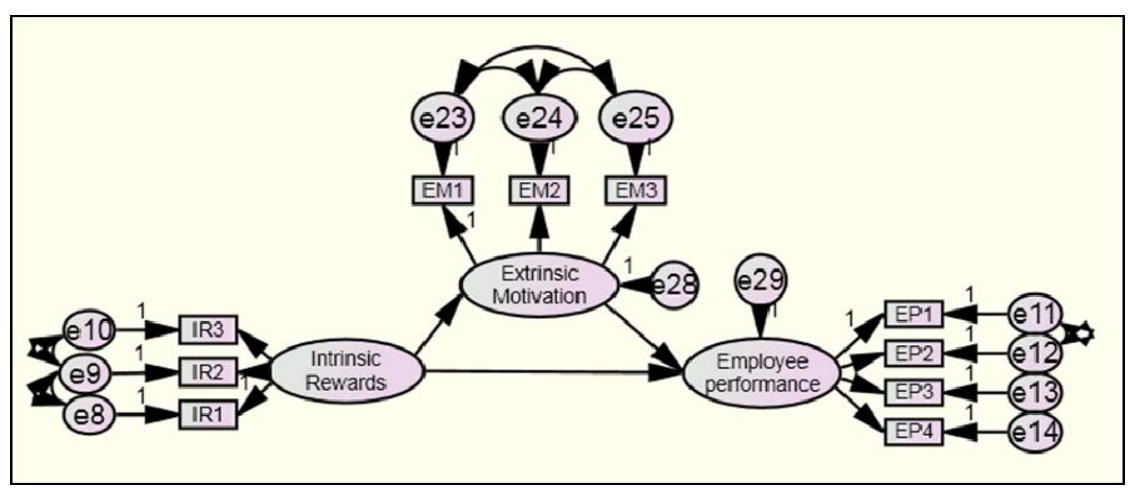

Figure 7. Structural model relating intrinsic rewards to intrinsic motivation and employee performance

Table 9

Model Fitness

\begin{tabular}{ccccccc}
\hline CMIN/DF & RMR & GFI & AGFI & CFI & RMSEA & PCLOSE \\
\hline 2.64 & 0.05 & 0.93 & 0.89 & 0.96 & 0.07 & 0.005 \\
\hline
\end{tabular}

Variables in Table 10 indicated the significant association of variables with one another because regression weights of relationships exceeded 0 .

Table 10

Standardized Regression Weights of Second Model

\begin{tabular}{cccc}
\hline & & & Estimate \\
\hline Extrinsic Motivation & $<---$ & Intrinsic Rewards & .58 \\
Employee Performance & $<---$ & Intrinsic Rewards & .38 \\
Employee Performance & $<---$ & Extrinsic Motivation & .29 \\
\hline
\end{tabular}

Table 11 summarizes the descriptive statistics of intrinsic rewards, extrinsic motivation, and employee performance.

Table 11

Descriptive Statistics of Third Model

\begin{tabular}{ccccccc}
\hline & Mean & $\begin{array}{c}\text { Standard } \\
\text { Deviation }\end{array}$ & $\begin{array}{c}\text { Reliability } \\
\alpha\end{array}$ & $\begin{array}{c}\text { Intrinsic } \\
\text { Rewards }\end{array}$ & $\begin{array}{c}\text { Extrinsic } \\
\text { Motivation }\end{array}$ & $\begin{array}{c}\text { Employee } \\
\text { Performance }\end{array}$ \\
\hline Intrinsic Rewards & 3.86 & 0.69 & 0.66 & 1 & & \\
Job Satisfaction & 3.43 & 0.90 & 0.76 & $.34^{* *}$ & 1 & \\
Employee Performance & 4.06 & 0.59 & 0.68 & $.43^{* *}$ & $.38^{* *}$ & 1 \\
\hline
\end{tabular}

\section{Evaluating Model Fitness}

These results indicated that the measurement model recognized as a good fit. 


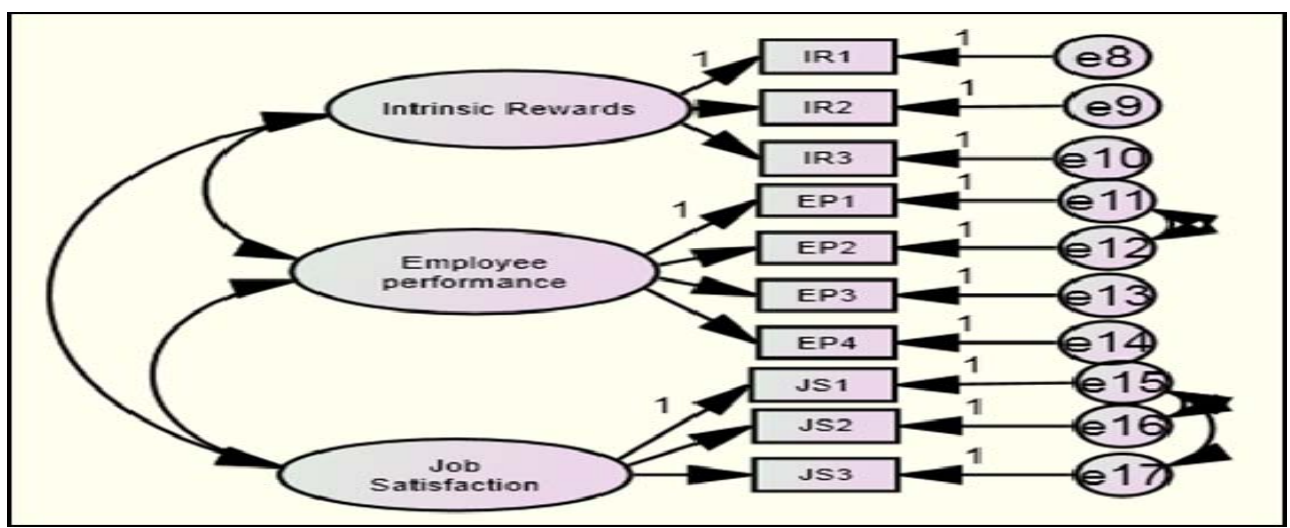

Figure 8. The measurement model

Table 12

Standardized Regression Weights of Third Model

\begin{tabular}{ccc}
\hline Latent Variable & Item Label & Standardized Factor Loading \\
\hline Intrinsic Rewards & $\mathrm{IR}_{1}$ & .56 \\
& $\mathrm{IR}_{2}$ & .60 \\
Job Satisfaction & $\mathrm{IR}_{3}$ & .72 \\
& $\mathrm{JS}_{1}$ & .71 \\
& $\mathrm{JS}_{2}$ & .83 \\
Employee Performance & $\mathrm{JS}_{3}$ & .82 \\
& $\mathrm{EP}_{1}$ & .45 \\
& $\mathrm{EP}_{2}$ & .51 \\
& $\mathrm{EP}_{3}$ & .67 \\
& $\mathrm{EP}_{4}$ & .59 \\
\hline
\end{tabular}

Table 13

Model Fit Summary of Second Model

\begin{tabular}{ccc} 
Model Fit Indices & Measurement & Threshold \\
\hline CMIN/DF & 2.47 & $<3$ good; $<5$ permissible \\
CFI & & Closer to $1 ;$ good \\
GFI & 0.94 & $>0.90$ \\
AGFI & 0.90 & $<0.80$ \\
RMR & 0.04 & $<0.06$ \\
RMSEA & 0.07 & $<0.06$ \\
PCLOSE & 0.02 & $>0.05$
\end{tabular}

\section{Structural Equation Modeling for Third Model}

CMIN/DF value was 3.08 suggesting that the above model was fit because its value was closer to 3. The value of GFI and AGFI specified that the model had fitness because all values were close to 0.90 . RMSEA and RMR values were 0.08 and 0.06 that were below 0.10 proposing that the estimated model was statistically fit as illustrated in Figure 9 and Table 14. Accordingly, all fit indices showed that the fitness of model was acceptable. 
Table 14

Model Fitness

\begin{tabular}{ccccccc}
\hline Model Fitness & & & & & \\
CMIN/DF & RMR & GFI & AGFI & CFI & RMSEA & PCLOSE \\
\hline 3.08 & 0.06 & 0.91 & 0.87 & 0.95 & 0.08 & 0.00 \\
\hline
\end{tabular}

As Table 15 illustrates, there was significant association of variables with one another because regression weights of relationships exceeded 0 .

Table 15

Standardized Regression Weights of Third Model

\begin{tabular}{cccc} 
& & & Estimate \\
\hline Job Satisfaction & $<---$ & Intrinsic Rewards & .41 \\
Employee Performance & $<---$ & Intrinsic Rewards & .43 \\
Employee Performance & $<---$ & Job Satisfaction & .30 \\
\hline
\end{tabular}

\section{Discussion}

The results of the study revealed that intrinsic motivation and extrinsic rewards significantly mediate the relationship between intrinsic rewards and task performance while job satisfaction in this regard partially mediates this relationship. The mediation value was also significant $(p=0.00<0.01)$.

Like all other empirical research studies, this study had also some limitations. The sample size was not adequate to represent the whole banking sector of Pakistan and there was likelihood that the future research in the same sector may yield a little bit different results. Another limitation is generalization of the findings from this study because data was gathered from a specific city, i.e., Lahore; hence, the results may not be applicable to other cities of Pakistan.

This study provides an integrated model to understand and better explain the relationship between organizational intrinsic rewards, extrinsic motivation, intrinsic motivation, job satisfaction, and task performance of personnel working in banking sector of Pakistan. This study might stimulate the researchers to begin to think deliberately about how the intrinsic rewards relates to motivation, how the extrinsic and intrinsic motivation help to contribute in the enhancement of task performance of employees working in respective organizations. In this century, organizations are required to develop such strategies regarding appreciation and motivational techniques for their employees that will help them to make contribution for the wellbeing of organizations due to their effective task performance. 


\section{Conclusion}

The present study was an attempt to find the relationship between an aspect of reward management system (intrinsic rewards), key determinants of motivation (intrinsic motivation and extrinsic motivation), and task performance. The findings of the present study indicated that intrinsic rewards moderately correlated with task performance and there was a full mediation of extrinsic and intrinsic motivation and slightly low mediation of job satisfaction with the dependent and independent variables of the study. The employees who are appreciated by intrinsic rewards within the organization not only perform well according to their job description but also get motivated positively for the welfare of organization and for them. Employees struggle when their organization appreciate their work, reward them, respect them and consider them as a vital part of the organization. The employees efficiently do their jobs, behave effectively in the organization, and remain loyal to their organization. Reward management system and performance appraisal techniques can be improved by paying attention on human resource management approaches that improve the performance of the organization.

\section{References}

Abdullah, A. (1994). Leading and motivating the Malaysian workforce. Malaysian Management Review, 29(3), $24-41$.

Adams, J. S. (1963). Towards an understanding of inequity. Journal of Abnormal Psychology, 67, 422-436.

Amabile, T. M., Hill, K. G., Hennessey, B. A., \& Tighe, E. M. (1994). The work preference inventory: Assessing intrinsic and extrinsic motivational orientations. Journal of Personality \& Social Psychology, 66(5), 950-967.

Awasthi, V., \& Pratt, J. (1990). The effects of monetary incentives on effort and decision performance: The role of cognitive characteristics. Accounting Review, 65(4), 797-811.

Baron, H., Henley, S., McGibbon, A., \& McCarthy, T. (2002). Motivation questionnaire manual and user's guide. Sussex: Saville and Holdsworth Limited.

Bhatnagar, J. (2007). Talent management strategy of employee engagement in Indian ITES employees: Key to retention. Employee Relations, 29(6), 640-663.

Cropanzano, R., \& Mitchell, M. S. (2005). Social exchange theory: An interdisciplinary review. Journal of Management, 31(6), 874-900.

Danish, R. Q., \& Usman, A. (2010). Impact of reward and recognition on job satisfaction and motivation: An empirical study from Pakistan. International Journal of Business \& Management, 5(2), 159-167.

Deci, E. L., \& Ryan, R. M. (1985). Intrinsic motivation and self-determination in human behavior. New York: Plenum.

Demirci, M. (2007). The effect of motivation tools on employee performance: An application on an automotive company in turkey (Unpublished master's thesis). Marmara University, Institute of Social Sciences, Turkey.

Eisenberger, R., \& Rhoades, L. (2001). Incremental effects of reward on creativity. Journal of Personality \& Social Psychology, 81(4), 728-741.

Galbraith, J. K. (1973). Controls or competition-what's at issue? The Review of Economics \& Statistics, 55(4), 524-538.

Goodale, J. C., Koerner, M., \& Roney, J. (1997). Analyzing the impact of service provider empowerment on perceptions of service quality inside an organization. Journal of Quality Management, 2(2), 191-215.

Harpaz, I. (1990). The importance of work goals: An international perspective. Journal of International Business Studies, 21(1), 75-93. 
Kinicki, A., \& Kreitner, R. (2006). Organizational behavior: Key concepts, skills and best practices ( $2^{\text {nd }}$ ed.). New York: McGraw-Hill/Irwin.

Klein, B. D., Goodhue, D. L., \& Davis, G. B. (1997). Can humans detect errors in data? Impact of base rates, incentives, and goals. MIS Quarterly, 21(2), 169-194.

Leete, L. (2000). Wage equity and employee motivation in nonprofit and for-profit organizations. Journal of Economic Behavior \& Organization, 43(4), 423-446.

Luthans, K. W., \& Sommer, S. M. (2005). The impact of high performance work on industry-level outcomes. Journal of Managerial Issues, 17(3), 327-345.

Markova, G., \& Ford, C. (2011). Is money the panacea? Rewards for knowledge workers. International Journal of Productivity and Performance Management, 60(8), 813-823.

Milne, P. (2007). Motivation, incentives and organisational culture. Journal of Knowledge Management, 11(6), $28-38$.

Nohria, N., Groysberg, B., \& Lee, L. (2008). Employee motivation: A powerful new model. Harvard Business Review, 86(7/8), 78-84.

Rusbult, C. E., \& Farrell, D. (1983). A longitudinal test of the investment model: The impact on job satisfaction, job commitment, and turnover of variations in rewards, costs, alternatives, and investments. Journal of Applied Psychology, $68(3), 429-439$.

Skinner, B. F. (1953). Science and human behavior. New York: Simon and Schuster.

Spector, P. (1997). Job satisfaction: Application, assessment, causes and consequences. London: Sage Publication.

Vroom, V. H. (1964). Work and motivation. New York: John Willey \& Sons.

Yang, H. (2008). Efficiency wages and subjective performance pay. Economic Inquiry, 46(2), 179-196. 